\title{
On the Hydration State of Amino Acids and Their Derivatives at Different Ionization States: A Comparative Multinuclear NMR and Crystallographic Investigation
}

\author{
Charalampos G. Pappas, Andreas G. Tzakos, and Ioannis P. Gerothanassis \\ Section of Organic Chemistry and Biochemistry, Department of Chemistry, University of Ioannina, 45110 Ioannina, Greece \\ Correspondence should be addressed to Ioannis P. Gerothanassis, igeroth@uoi.gr
}

Received 15 December 2011; Accepted 8 March 2012

Academic Editor: Heather M. Wallace

Copyright (C) 2012 Charalambos G. Pappas et al. This is an open access article distributed under the Creative Commons Attribution License, which permits unrestricted use, distribution, and reproduction in any medium, provided the original work is properly cited.

${ }^{2} \mathrm{D},{ }^{13} \mathrm{C},{ }^{14} \mathrm{~N}$, and ${ }^{17} \mathrm{O} \mathrm{NMR}$ and crystallographic data from the literature were critically evaluated in order to provide a coherent hydration model of amino acids and selected derivatives at different ionization states. ${ }^{17} \mathrm{O}$ shielding variations, longitudinal relaxation times $\left(T_{1}\right)$ of ${ }^{2} \mathrm{D}$ and ${ }^{13} \mathrm{C}$ and line widths $\left(\Delta \nu_{1 / 2}\right)$ of ${ }^{14} \mathrm{~N}$ and ${ }^{17} \mathrm{O}$, may be interpreted with the hypothesis that the cationic form of amino acids is more hydrated by 1 to 3 molecules of water than the zwitterionic form. Similar behaviour was also observed for $\mathrm{N}$-acetylated derivatives of amino acids. An exhaustive search in crystal structure databases demonstrates the importance of six-membered hydrogen-bonded conjugated rings of both oxygens of the $\alpha$-carboxylate group with a molecule of water in the vicinity. This type of hydrogen bond mode is absent in the case of the carboxylic groups. Moreover, a considerable number of structures was identified with the propensity to form intramolecular hydrogen bond both in the carboxylic acid ( $\mathrm{NH} \cdots \mathrm{O}=\mathrm{C})$ and in the carboxylate $\left(\mathrm{NH} \cdots \mathrm{O}^{-}\right)$ionization state. In the presence of bound molecules of water this interaction is significantly reduced in the case of the carboxylate group whereas it is statistically negligible in the carboxylic group.

\section{Introduction}

Water plays a fundamental role in the conformation and activity of every biological macromolecule [1]. Peptide- and protein- hydration is the dominant factor in the stabilization of spatial molecular structure, in the process of protein folding by gating hydrophobic residues, and in the mechanisms of peptide and protein mediated reactions [1-4]. Water molecules, therefore, can be considered as an integral component of biomolecular systems with dynamic, functional, and structural roles [4-7]. Investigation of the structural and functional role of water molecules, bound to proteins and peptides, requires a sufficient understanding of the hydration process of their building blocks $[1,2]$. The hydration of amino acids and their derivatives at a molecular level, therefore, is of great importance and has been extensively studied with X-ray crystallography $[1,3]$ and a variety of spectroscopic techniques including multinuclear magnetic resonance spectroscopy $[2,8-13]$, IR and Raman spectroscopy [14-16], ICR mass spectrometry [17], and laser ablation in combination with microwave spectroscopy [18].

We present here, for the first time in the international literature, a comparative investigation of literature ${ }^{2} \mathrm{D},{ }^{13} \mathrm{C}$, ${ }^{14} \mathrm{~N}$, and ${ }^{17} \mathrm{O}$ NMR and crystallographic data in order to provide a coherent hydration model of amino acids and selected derivatives at different ionization states in aqueous solution and in the crystal state.

\section{Results and Discussion}

2.1. ${ }^{17} \mathrm{O}$ NMR Shieldings. ${ }^{17} \mathrm{O}$ NMR has received little attention in amino acid and peptide research $[2,12,13$, $19,20]$. This neglect is due to the fact that of the three naturally occurring oxygen isotopes, only ${ }^{17} \mathrm{O}$ possesses a nuclear spin $(I=5 / 2)$. Owing to its electric quadrupole moment $\left(\mathrm{Qe}=-2.6 \times 10^{-30} \mathrm{em}^{2}\right)$ and, thus, broad line widths, and its low absolute sensitivity com-pared with that of ${ }^{1} \mathrm{H}\left(\sim 1.1 \times 10^{-5}\right)$, the ${ }^{17} \mathrm{O}$ - isotope is one of 

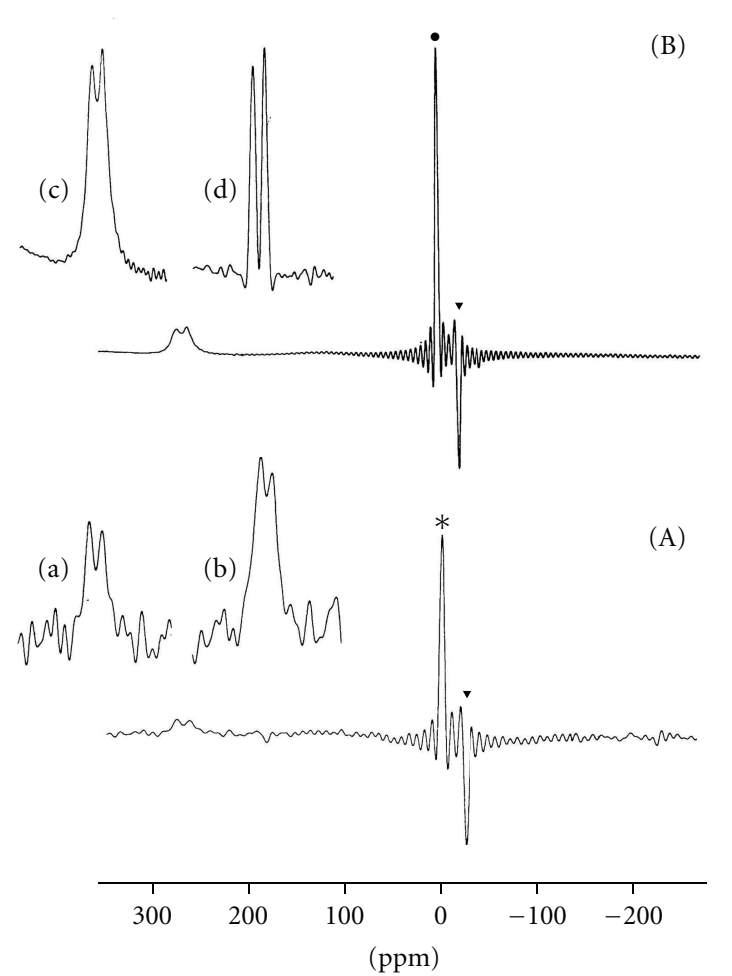

Figure 1: $27.11 \mathrm{MHz}{ }^{17} \mathrm{O}$ NMR spectra of $0.1 \mathrm{M}$ solutions of glutamic acid in $\mathrm{H}_{2} \mathrm{O}$ containing $1 \mathrm{M} \mathrm{NaCl}$, temperature $=40^{\circ} \mathrm{C}$, $\mathrm{pH}=3.1$. (a) Natural abundance spectrum in ${ }^{17} \mathrm{O}$ depleted water $\left.{ }^{*}\right) . T_{\text {acq }}=5 \mathrm{~ms}$, NS $=3 \times 10^{6}$, total experimental time ca.4.2 h; $\nabla$ transmitter's residual peak. Glutamic acid resonances after (a) vertical expansion (8x); (b) exponential multiplication of the FID $(\mathrm{LB}=100 \mathrm{~Hz})$. (b) Spectrum of $1 \%$ enriched glutamic acid in ordinary water $(\bullet) . T_{\text {acq }}=7.5 \mathrm{~ms}$, NS $=150,000$, total experimental time ca. 19 min. Glutamic acid resonances after (c) vertical expansion (8x); (d) multiplication of the FID with a Gaussian-exponential function. (Reprinted, with permission, from Helv. Chim. Acta [23]. Copyright 1982, by Swiss Chemical Society).

the more difficult to observe by NMR spectroscopy [12, $13,21,22] .{ }^{17} \mathrm{O}$ NMR studies, therefore, of compounds at natural abundance require high concentrations $(>0.1 \mathrm{M})$ and extensive signal averaging. Recording of spectra can be greatly facilitated by the use of ${ }^{17} \mathrm{O}$ enriched samples [2327]. Figure $1(\mathrm{a})$ illustrates the natural abundance ${ }^{17} \mathrm{O}$ NMR spectrum of glutamic acid, $0.1 \mathrm{M}$ in ${ }^{17} \mathrm{O}$-depleted water at $40^{\circ} \mathrm{C}$. Despite the extensive signal averaging (number of scans (NS) $=3 \times 10^{6}$ ) and the total experimental time of 4.2 hours, the achievable signal-to-noise $(S / N)$ ratio is very poor and practically prohibitive for the accurate determination of chemical shifts and line widths. Figure 1(b) illustrates the clear advantages of working with ${ }^{17} \mathrm{O}$-labelled glutamic acid $\left({ }^{17} \mathrm{O}\right.$ enrichment 1 at.\%) [23].

${ }^{17} \mathrm{O}$ shieldings of various chemical functional groups are very sensitive for studying hydrogen bonding interactions because of the large chemical shift range of the ${ }^{17} \mathrm{O}$ nucleus $[12,13]$. The effect of solvent-induced hydrogen bonding interactions on $\delta\left({ }^{17} \mathrm{O}\right)$ of the carboxyl groups is, however, rather small compared with the substantial sensitivity of over $80 \mathrm{ppm}$ to hydrogen bonding interaction of $\delta\left({ }^{17} \mathrm{O}\right)$ of amide and carbonyl oxygens $[12,13]$. Only a single ${ }^{17} \mathrm{O}$ resonance absorption is observed for the carboxylic group since the shifts of the individual resonance absorptions $\delta(\mathrm{C}=\mathrm{O})$ and $\delta(\mathrm{OH})$ are averaged out by rapid intermolecular proton transfer with protic solvents, traces of $\mathrm{H}_{2} \mathrm{O}$, and/or through hydrogen bonding aggregates of the $\mathrm{COOH}$ groups in organic solvents $[12,13,23,24,26,28]$. Reuben [29] from dilution studies of acetic acid in 1,2-dichloroethane estimated a deshielding effect of $\sim 12 \mathrm{ppm}$ due to breaking of a hydrogen bond involving the carbonyl oxygen of the acid and a shielding effect of $-6 \mathrm{ppm}$ due to breaking of a $\mathrm{OH} \cdots \mathrm{O}$ hydrogen bond. Therefore, a total shift of only $+6 \mathrm{ppm}$ is expected for the monomeric acetic acid in apolar media (dichloroethane) compared with the dimeric form.

Despite the relatively low sensitivity of the ${ }^{17} \mathrm{O}$ shieldings of the carboxyl group to hydrogen bond interactions, Spisni and collaborators [9] attempted to estimate the solvation state of the $\alpha$-carboxyl group of amino acids in the different ionization states. Figures 2(a) and 2(b) show the dependence of $\delta\left({ }^{17} \mathrm{O}\right)$ of $\mathrm{L}$-alanine and L-proline as a function of molar fraction of DMSO in the $\mathrm{pH}$ range 7-8 and 12-13. Since DMSO cannot form a hydrogen bond interaction with the carboxylate group, contrary to the case of $\mathrm{H}_{2} \mathrm{O}$, the shielding difference of $10-17 \mathrm{ppm}$ between the two solvents was interpreted with the hypothesis that the carboxylate group of these amino acids is hydrated by two water molecules in aqueous solution with one hydrogen bond per carboxylate oxygen. In the acidic $\mathrm{pH}$ range (Figures 2(c), 2(d)), a nonlinear behaviour of the chemical shift at high DMSO molar fractions was observed. For DMSO molar fractions up to 0.6, a linear dependence of the chemical shift was observed which, on extrapolation to $100 \%$ DMSO, results in a shielding of $15-17 \mathrm{ppm}$, the same as in the neutral $\mathrm{pH}$. This was interpreted with the hypothesis that two hydrogen bonds (one to each oxygen) are being ruptured. When the DMSO molar fraction is between 0.6 and 0.8 , it was suggested that a third molecule of water, which is hydrogen bonded to the hydroxyl hydrogen, is dissociated due to the interaction with DMSO. This might explain the deflection from linearity and the plateau-like dependence of the ${ }^{17} \mathrm{O}$ shielding. The protonated form, therefore, of the carboxyl group of the amino acids is more hydrated with an access of a bound molecule of $\mathrm{H}_{2} \mathrm{O}$ than the deprotonated form. This conclusion is in qualitative agreement with multinuclear NMR relaxation data (see below).

2.2. Multinuclear NMR Relaxation Data. For quadrupolar nuclei, such as ${ }^{2} \mathrm{D},{ }^{15} \mathrm{~N}$, and ${ }^{17} \mathrm{O}$, the longitudinal $\left(T_{1}\right)$ and transverse $\left(T_{2}\right)$ relaxation times are essentially due to quadrupolar interaction

$$
\frac{1}{T_{1}}=\frac{1}{T_{2}}\left(1+\frac{\eta^{2}}{3}\right) \chi^{2} f(\omega, D)
$$

where $\chi$ is the nuclear quadrupole coupling constant. The asymmetry parameter $\eta$ varies from 0 to 1 and describes the deviation of the electric field gradient from axial symmetry, and $f(\omega, D)$ is the correlation function, which depends on 


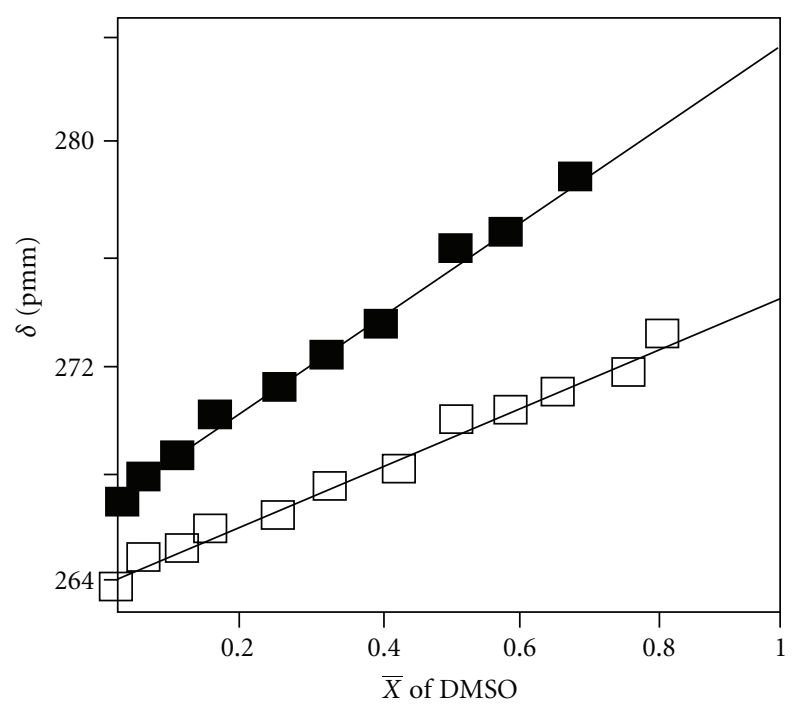

(a)

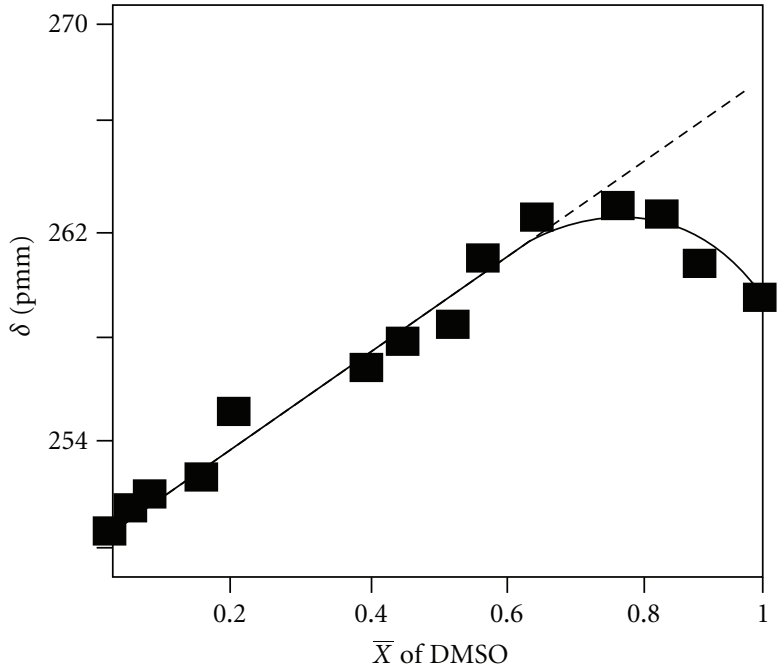

(c)

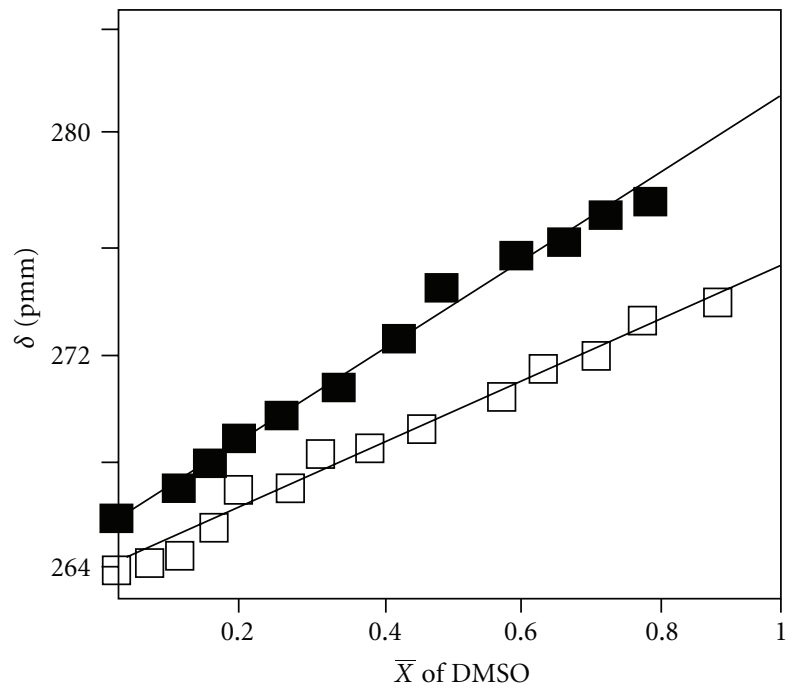

(b)

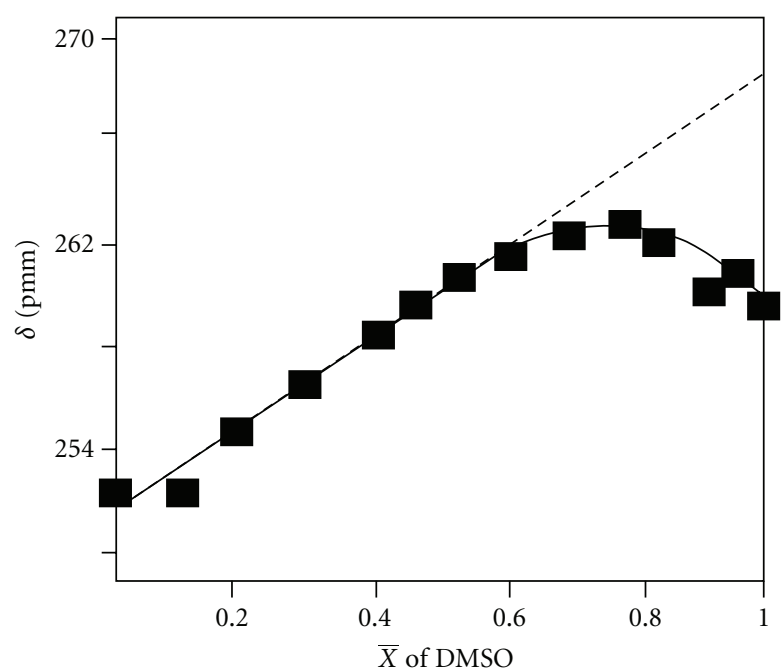

(d)

FIGURE 2: Dependence of the ${ }^{17} \mathrm{O}$ chemical shift (ppm from $\mathrm{H}_{2} \mathrm{O}$ ) of L-alanine and L-proline on the molar fraction $\mathrm{X}$ of DMSO at various pH values. (a) L-alanine at pH $7.4(\mathbf{\square})$ and pH 11.9 ( $\square$ ), (b) L-proline at pH 8.3 (ם) and pH 13.0 ( $\square$ ), (c) L-alanine at pH 1.5, and (d) L-proline at pH 1.0. (Adapted, with permission, from Biochem. Biophys. Res. Commun. [9]. Copyright 1986, Academic Press, Inc.).

the rotational diffusion constant $D$ and its relative orientation with respect to the principal axes of the field gradient tensor $[12,13]$. When isotropic reorientation is assumed, $f(\omega, D)$ reduces to a single overall correlation time $\tau_{\text {mol }}$ which is given by the Stokes-Debye formula

$$
\tau_{\mathrm{mol}}=\frac{V_{m} \eta_{v}}{k_{B} T}
$$

where $V_{m}$ is the molecular volume, $\eta_{v}$ the viscosity of the solution, $k_{B}$ the Boltzman constant, and $T$ the absolute temperature. $V_{m}$ can be estimated as

$$
V_{m}=\frac{0.74 \mathrm{MW}}{N_{0} \rho},
$$

where $N_{0}$ is the Avogadro's number and MW and $\rho$ are the molecular weight and the density of the solute (amino acid), respectively.

Paramagnetic impurities shorten the relaxation times and might lead to erroneous results. The removal, therefore, of these impurities is necessary in studies of $T_{2}$ and $T_{1}$ relaxation times. Figure 3 illustrates the $\mathrm{pH}$ dependence of the ${ }^{17} \mathrm{O}$ line widths of $0.1 \mathrm{M}$ glycine in $\mathrm{H}_{2} \mathrm{O}$ [24]. A broad minimum between $\mathrm{pH} 4$ and 7 was observed. This ${ }^{17} \mathrm{O}$ line width minimum has been previously explained by a decrease of the molecular tumbling time attributable to a reduction in hydration and, thus, intermolecular association of glycine in the zwitterionic form [26]. In the high $\mathrm{pH}$ region, a broad maximum at $\mathrm{pH} \approx 11$ was observed. Addition of $2 \mathrm{mM}$ ethylenediamine- $\mathrm{N}, \mathrm{N}, \mathrm{N}^{\prime}, \mathrm{N}^{\prime}$-tetraacetate (EDTA) to 


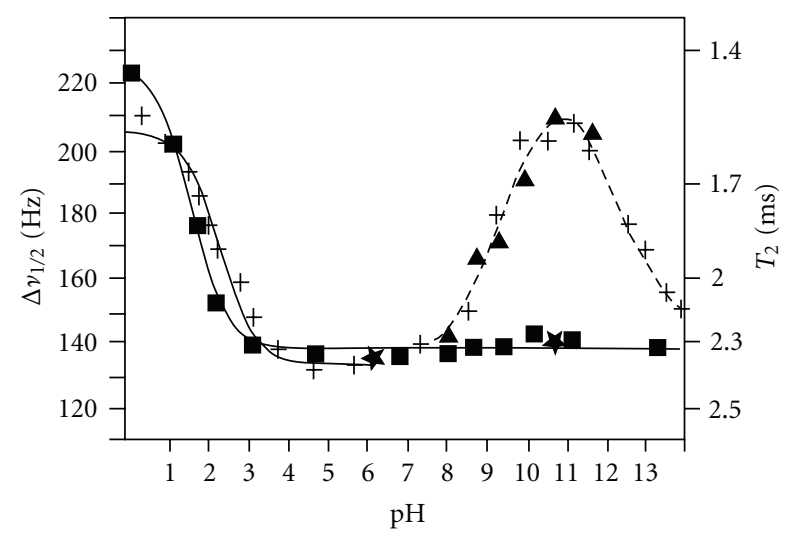

Figure 3: The pH-dependence of the ${ }^{17} \mathrm{O}$ NMR linewidth of $0.1 \mathrm{M}$ glycine in $\mathrm{H}_{2} \mathrm{O}$ which contained $1 \mathrm{M} \mathrm{NaCl}$; temperature $40^{\circ} \mathrm{C}$; (+) measured at $27.11 \mathrm{MHz} ;(\boldsymbol{\Delta})$ at $12.2 \mathrm{MHz} ;(\boldsymbol{\square})$ at $27.11 \mathrm{MHz}$ after addition of 2 mM EDTA (ethylenediamine-N,N,N,N-tetraacetate). The dashed lines were drawn to follow the experimental points. The solid lines correspond to a nonlinear least-squares fit to one proton titration curve. $(\star)$ are $T_{1}$ values $(\mathrm{ms})$ measured at $27.11 \mathrm{MHz}$. (Reprinted, with permission, from Helv. Chim. Acta [24]. Copyright 1982, by Swiss Chemical Society.).

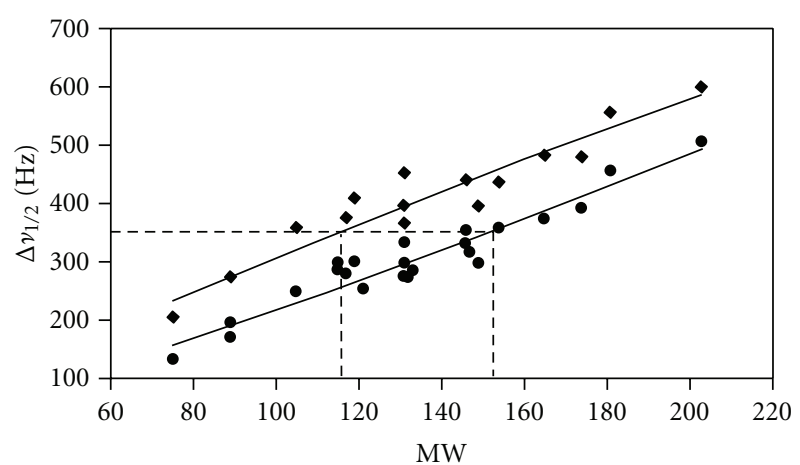

(a)

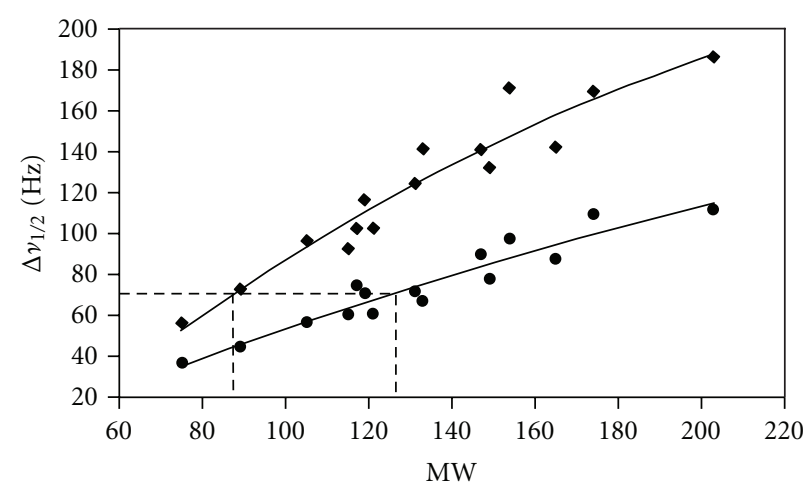

(b)

Figure 4: Plot of the ${ }^{14} \mathrm{~N}(28.9 \mathrm{MHz})$ (a) and ${ }^{17} \mathrm{O}(48.8 \mathrm{MHz})(\mathrm{b})$ line widths, $\Delta v_{1 / 2}$, of Table 1 of the protein amino acids versus their molecular weights, MW: $(\downarrow) \mathrm{pH} 0.5,(\bullet) \mathrm{pH}$ 6.0. All lines correspond to a nonlinear least squares fit of the experimental points of Table 1 according to (7). Dotted lines indicate the difference in MW for the same $\Delta v_{1 / 2}$ values. (Reprinted, with permission, from J. Magn. Reson. [11]. Copyright 2003, by Elsevier Inc.). the original solution resulted in no line width variation in the neutral and high $\mathrm{pH}$ region. It can, therefore, be concluded that this broad minimum at $\mathrm{pH} \approx 11$ should be attributed to the effect of paramagnetic impurities and not to a hydration change of glycine in the neutral and high $\mathrm{pH}$ region [24].

${ }^{2} \mathrm{D} T_{1}$ relaxation times of $\mathrm{C}_{\alpha} \mathrm{D}_{2}$ of glycine at acidic $\mathrm{pH}$ were shown to be shorter relative to those at neutral $\mathrm{pH}$ [8]. This shortening in $T_{1}$ implies an increase in $\tau_{\text {mol }}$ and, thus, in the effective molecular weight MW ((1), (2a), and (2b)), which was interpreted with an increase in the hydration state in the cationic form.

Tritt Goc and Fiat [30] investigated in detail the viscosity and temperature dependence of the ${ }^{17} \mathrm{O}$ NMR line width of glycine, alanine, proline, leucine, histidine, and phenylalanine at $\mathrm{pH} 2,7$, and 12.5. The experimentally observed viscosity/temperature $\left(\eta_{v} / T\right)$ dependence of the reorientation correlation time was compared with various hydrodynamic models. A model of the hydration state in the primary solvation sphere of the carboxylic group of amino acids in their cationic state was suggested in which two water molecules are hydrogen bonded to the oxygens and one to the hydrogen of the $\mathrm{OH}$ group. In the zwitterionic and anionic states, the hydration model of the carboxylate group can be presented by a structure in which one water molecule is hydrogen bonded to each of the oxygens [30].

The ${ }^{17} \mathrm{O}[10,11]$ and ${ }^{14} \mathrm{~N}$ NMR [11] line widths of several protein amino acids were measured in aqueous solution to investigate the effect of molecular weight on the line widths (Table 1). The ${ }^{14} \mathrm{~N}$ and ${ }^{17} \mathrm{O}$ line widths, under composite proton decoupling, increase with the bulk of the amino acid, and increase at low $\mathrm{pH}$. Assuming an isotropic molecular reorientation of a rigid sphere and, thus, a single correlation time from overall molecular reorientation $\left(\tau_{\mathrm{mol}}\right)$, then, the line width $\Delta v_{1 / 2}$ can be expressed in the following form [11]:

$$
\Delta \nu_{1 / 2}=\frac{1}{\pi T_{2}}=\alpha_{0}+\alpha_{1} \mathrm{MW}
$$

where MW is the molecular weight, $\alpha_{1}$ is the contribution to the line width of the quadrupolar coupling constant, density and temperature, (1), (2a), and (2b), and $\alpha_{0}$ is the solvent viscosity-independent contributions to the line width due to the primary hydration sphere of the amino acids.

The linear correlation between $\Delta v_{1 / 2}$ and $\mathrm{MW}$ at $\mathrm{pH} 6$ for both ${ }^{14} \mathrm{~N}$ and ${ }^{17} \mathrm{O}$ nuclei (Figure 4 ) is in agreement with the hydrodynamic model of (3) [11]. Furthermore, the $\chi\left({ }^{17} \mathrm{O}\right)$ of the amino acid is independent of both the ionization and the degree of hydration of the carboxyl group [10]. The increase in the ${ }^{17} \mathrm{O}$ line widths at acidic $\mathrm{pH}(\sim 100 \pm 31 \mathrm{~Hz})$, relative to those at neutral $\mathrm{pH}$, was interpreted by a change in the rotational correlation time and, thus, effective MW of the amino acids, (3). This implies that the cationic form of the amino acids is more hydrated by an access of 1.3 to 2.5 molecules of water relative to that in the zwitterionic form [11] with lifetimes that are longer than the overall molecular rotational correlation time, presumably $2-10$ ps [10].

In the case of a stochastic diffusion of the amino and carboxyl groups comprising contributions from internal 
TABLe 1: ${ }^{14} \mathrm{~N}$ (at $28.9 \mathrm{MHz}$ ) and ${ }^{17} \mathrm{O}\left(\right.$ at $48.8 \mathrm{MHz}$ ) linewidths, $\Delta \nu_{1 / 2}$, of protein amino acids in different ionization states ${ }^{* a}$.

\begin{tabular}{|c|c|c|c|c|c|}
\hline \multirow{3}{*}{ Amino Acid } & \multirow{3}{*}{$\mathrm{MW}^{\mathrm{f}}$} & \multicolumn{4}{|c|}{$\Delta \nu_{1 / 2}, \mathrm{~Hz}^{\mathrm{b}, \mathrm{c}}$} \\
\hline & & \multicolumn{2}{|c|}{$\mathrm{pH} 0.5$} & \multicolumn{2}{|c|}{$\mathrm{pH} 6.0$} \\
\hline & & ${ }^{14} \mathrm{~N}$ & ${ }^{17} \mathrm{O}$ & ${ }^{14} \mathrm{~N}$ & ${ }^{17} \mathrm{O}$ \\
\hline Gly & 75.07 & $55(67)$ & $205(233)$ & $36(40)$ & $132(131)$ \\
\hline Ala & 89.10 & $71(79)$ & $276(274)$ & $45(49)$ & $194(172)$ \\
\hline Sar & 89.10 & $83(80)$ & $272(274)$ & $60(49)$ & $170(172)$ \\
\hline N,N-dimethyl-Gly & 103.10 & & $329(314)$ & & $198(212)$ \\
\hline Ser & 105.09 & $97(94)$ & $359(320)$ & $57(58)$ & $249(218)$ \\
\hline Pro & 115.13 & $87(104)$ & $286(349)$ & $60(64)$ & $197(247)$ \\
\hline Val & 117.15 & $102(105)$ & $376(355)$ & $72(65)$ & $280(253)$ \\
\hline Thr & 119.12 & $118(107)$ & $410(360)$ & $71(66)$ & $300(259)$ \\
\hline Cys & 121.26 & $104(109)$ & e & $59(67)$ & $254(265)$ \\
\hline 4-hydroxy-Pro & 131.13 & & $366(395)$ & & $275(293)$ \\
\hline Ile & 131.18 & $115(118)$ & $453(395)$ & $65(73)$ & 335 (294) \\
\hline Leu & 131.18 & $124(118)$ & $397(395)$ & $71(72)$ & $298(294)$ \\
\hline Asn & 132.12 & $\mathrm{~d}$ & e & $\mathrm{d}$ & $274(296)$ \\
\hline Asp & 133.11 & $140(120)$ & d & $65(74)$ & 285 (299) \\
\hline Gln & 146.15 & d & e & $\mathrm{d}$ & $330(337)$ \\
\hline Lys & 146.19 & $\mathrm{~d}$ & 443 (439) & $\mathrm{d}$ & 354 (337) \\
\hline Glu & 147.13 & $146(133)$ & $\mathrm{d}$ & $89(82)$ & $316(340)$ \\
\hline Met & 149.21 & $133(135)$ & 397 (448) & $78(83)$ & $297(346)$ \\
\hline His & 155.16 & $169(140)$ & $438(465)$ & $99(86)$ & 359 (363) \\
\hline Phe & 165.19 & $143(150)$ & $485(494)$ & $88(93)$ & $376(392)$ \\
\hline Arg & 174.20 & 165 (159) & $482(520)$ & $111(98)$ & 394 (418) \\
\hline Tyr & 181.19 & $134(164)$ & $558(540)$ & $102(102)$ & $457(438)$ \\
\hline O-Methyl-Tyr & 195.19 & & $622(581)$ & & 525 (479) \\
\hline Trp & 204.23 & $180(186)$ & $602(607)$ & $108(115)$ & $508(505)$ \\
\hline
\end{tabular}

* Adapted, with permission, from J. Magn. Reson. [11]. Copyright 2003, by Elsevier Inc.

${ }^{a} 0.1 \mathrm{M}$ solutions in $\mathrm{H}_{2} \mathrm{O}$ containing $10^{-5} \mathrm{M}$ EDTA (ethylenediamine- $\mathrm{N}, \mathrm{N}, \mathrm{N}^{\prime}, \mathrm{N}^{\prime}$-tetraacetate); $T=40^{\circ} \mathrm{C}$

${ }^{b}$ Linewidths at half-height, estimated errors $< \pm 5 \%$.

${ }^{\mathrm{c}}$ Values into parenthesis correspond to line widths resulting from regression analysis assuming isotropic molecular motion and linear approximation.

${ }^{\mathrm{d}}$ Overlapping resonances.

${ }^{\mathrm{e}}$ Not measured because of degradation.

${ }^{\mathrm{f}} \mathrm{MW}$ of the zwitterionic form.

$\left(\tau_{\text {int }}\right)$ and overall $\left(\tau_{\text {mol }}\right)$ motions, the correlation time $\tau_{c}$ for ${ }^{14} \mathrm{~N}$ or ${ }^{17} \mathrm{O}$ is given by [31]

$$
\tau_{c}=\tau_{\mathrm{mol}}\left[A+(B+C) \frac{(12 / r) \tau_{\mathrm{int}}}{\tau_{\mathrm{mol}}+(12 / r) \tau_{\mathrm{int}}}\right]
$$

with

$A=\frac{3}{4}\left(3 \cos ^{2} \theta-1\right)^{2}, \quad B=3 \sin ^{2} \theta \cos ^{2} \theta, \quad c=\frac{3}{4} \sin ^{4} \theta$,

where $\theta$ is the angle between the rotation axis and the main field gradient ( $r$ denotes an $r$-fold jump mechanism). Since the sum of $A, B$, and $C$ is equal to $1,(4 \mathrm{a})$ can be rewritten as

$$
\tau_{c}=\tau_{\mathrm{mol}} \frac{A \tau_{\mathrm{mol}}+\tau_{i}}{\tau_{\mathrm{mol}}+\tau_{i}},
$$

where

$$
\tau_{i}=\left(\frac{12}{r}\right) \tau_{\text {int }} .
$$

Equations (5a) and (5b) can be rewritten as

$$
\tau_{c}=(1-A) \tau_{i}+A \tau_{\mathrm{mol}}-\frac{(1-A) \tau_{i}^{2}}{\tau_{\mathrm{mol}}+\tau_{i}} .
$$

Since $A$ and $\tau_{i}$ can be assumed to be constant for all the amino acids, (4a) and (4b) can be written as

$$
\Delta \nu_{1 / 2}=\alpha_{0}+\alpha_{1} \mathrm{MW}+\frac{\alpha_{2}}{\mathrm{MW}+\alpha_{3}},
$$

where $\alpha_{0}-\alpha_{3}$ are constants. The minimization of (7) on the basis of the ${ }^{17} \mathrm{O}$ experimental data gave the mean difference of $35.8 \pm 17.3$ in MW between $\mathrm{pH} 0.5$ and 6.0 for three different $\Delta \nu_{1 / 2}$ values: 250, 350 (Figure $4(\mathrm{~b})$ ), and $500 \mathrm{~Hz}$. This was interpreted by an excess of $1-3$ water molecules at $\mathrm{pH}=0.5$.

The difference in the ${ }^{14} \mathrm{~N}$ line widths at the two ionization states (Figure 4(a)) should be attributed to differences in the correlation times and to a decrease in the $\chi\left({ }^{14} \mathrm{~N}\right)$ on deprotonation of the carboxyl group. In the case of the linear model, the influence of variations of values of the $\chi\left({ }^{14} \mathrm{~N}\right)$ to the line width, $\Delta \nu_{1 / 2}$, is less for small molecular weights. Therefore, for $\Delta \nu_{1 / 2}=70 \mathrm{~Hz}$ (Figure 4(a)), the difference in MW will be a reasonable approximation of the difference in hydration in the two states. The calculated value was found to be $45.2 \pm 7.4$, which corresponds to an excess of 2-3 water molecules in the cationic form compared to that in 


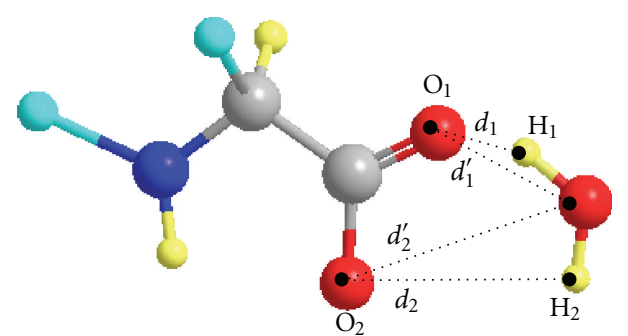

(a)

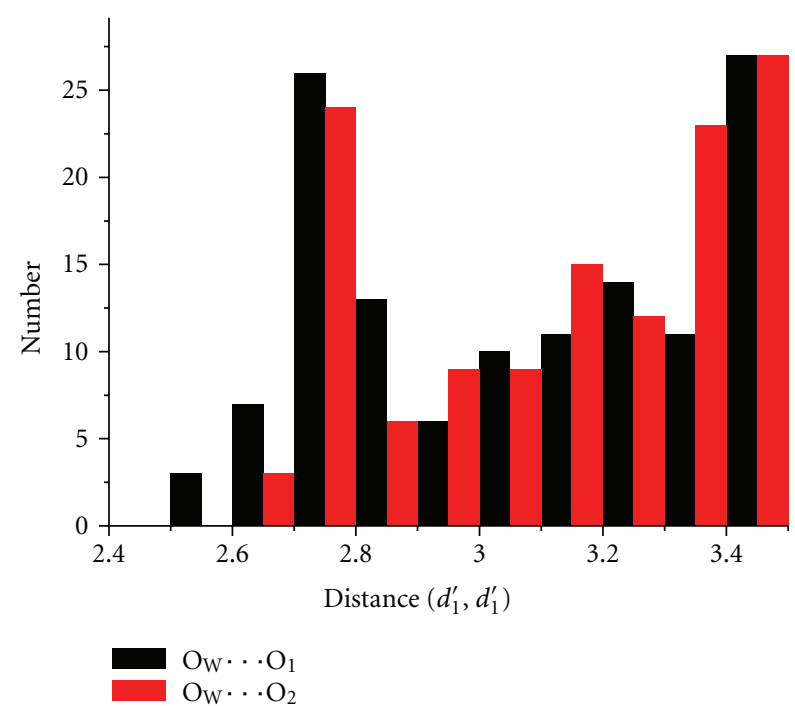

(c)

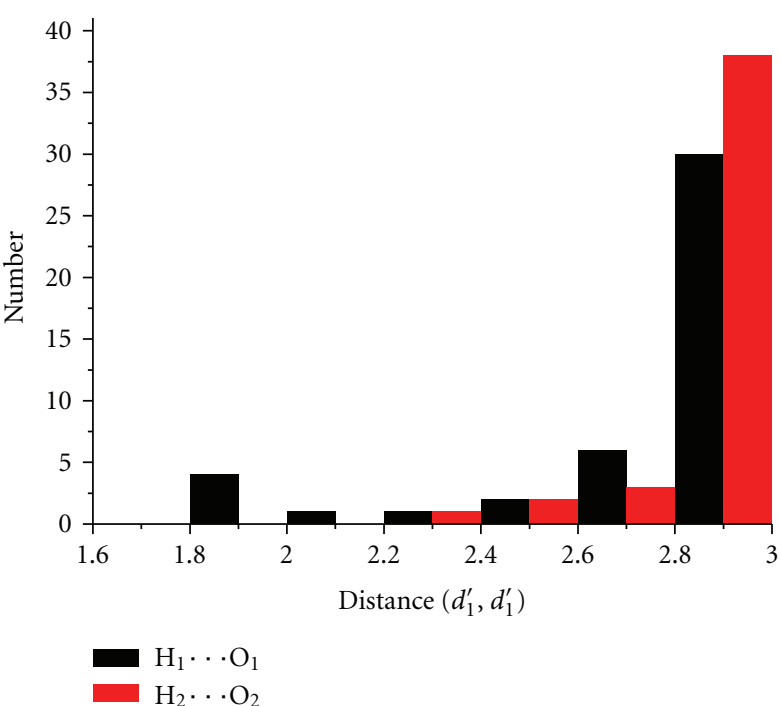

(b)

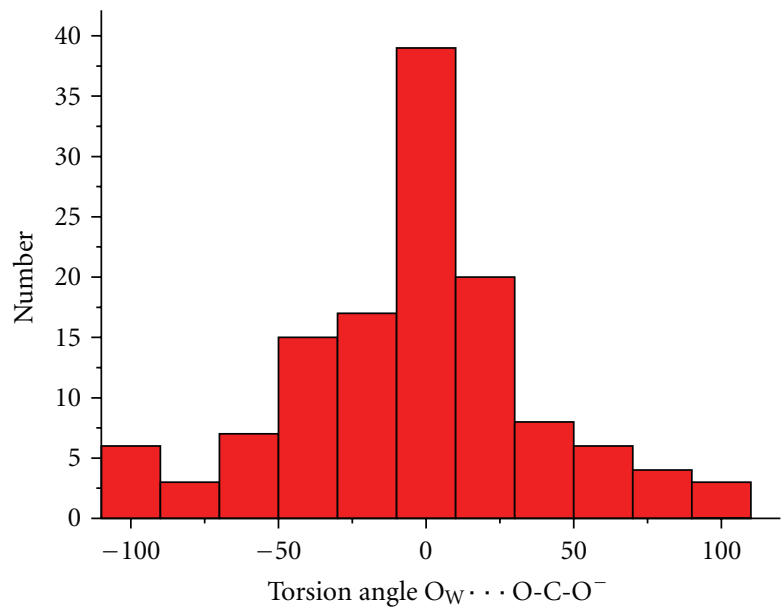

(d)

FIgure 5: (a) Cambridge Crystallographic Database (CSD) search queries for six-membered hydrogen bond conjugated rings between the two oxygens of the $\alpha$-carboxylate with a molecule of water in the vicinity. Hydrogen bonds and long-range dipolar interactions are defined by the geometric constraints $d_{1}$ and $d_{2} \leq 3 \AA$ and $d_{1}^{\prime}$ and $d_{2}^{\prime} \leq 3.5 \AA$. C (gray), $\mathrm{N}$ (blue), any group (cyan), $\mathrm{H}$ (light-yellow), and O (red). (b) Plot of the number of structures versus the distances $d_{1}\left(\mathrm{H}_{1} \cdots \mathrm{O}_{1}\right)$ and $d_{2}\left(\mathrm{H}_{2} \cdots \mathrm{O}_{2}\right)$. (c) Plot of the number of structures versus the distances $d_{1}^{\prime}\left(\mathrm{O}_{\mathrm{W}} \cdots \mathrm{O}_{1}\right)$ and $d_{2}^{\prime}\left(\mathrm{O}_{\mathrm{W}} \cdots \mathrm{O}_{2}\right)$. (d) Distribution of the torsion angle $\mathrm{O}_{1}-\mathrm{C}-\mathrm{O}_{2} \cdots \mathrm{O}_{\mathrm{W}}$ versus the number of structures.

the zwitterionic form, in reasonable agreement with the ${ }^{17} \mathrm{O}$ NMR data [11].

More recently, Takis et al. [32] investigated the $\mathrm{C}_{\alpha}^{13} \mathrm{C}$ longitudinal relaxation times $\left(T_{1}\right)$ and ${ }^{14} \mathrm{~N}$ line widths $\left(\Delta \nu_{1 / 2}\right)$ of amino acids and acetyl-amino acids in aqueous solutions at acid and neutral $\mathrm{pH}$. Both ${ }^{13} \mathrm{C}_{\alpha}$ and ${ }^{14} \mathrm{~N}$ values indicate that amino acids and acetyl-amino acids at acid $\mathrm{pH}$ interact with an access of one water molecule with respect to their deprotonated form at neutral $\mathrm{pH}$. On the contrary, ${ }^{13} \mathrm{C}_{\alpha}$ and ${ }^{14} \mathrm{~N}$ values of betaines $\left(\mathrm{R}_{3} \mathrm{~N}^{+} \mathrm{CH}(\mathrm{R}) \mathrm{COO}^{-}\right)$demonstrate no hydration differences in acid and neutral $\mathrm{pH}$ values.
2.3. Crystallographic Data and Statistics. Crystal structure databases provide a rich source of information to extract details on the architectures and interactions of molecules. This kind of search provides the opportunity to examine the formation of intramolecular and intermolecular hydrogen bond in small molecule crystal structures [33, 34]. Propensities for the hydration of the $\alpha$-carboxylate group of amino acids and their derivatives were derived on the basis of exhaustive searches in the Cambridge Crystallographic Database (CSD). Since intermolecular hydrogen bonds are preferred when five- or six-membered conjugated rings are 


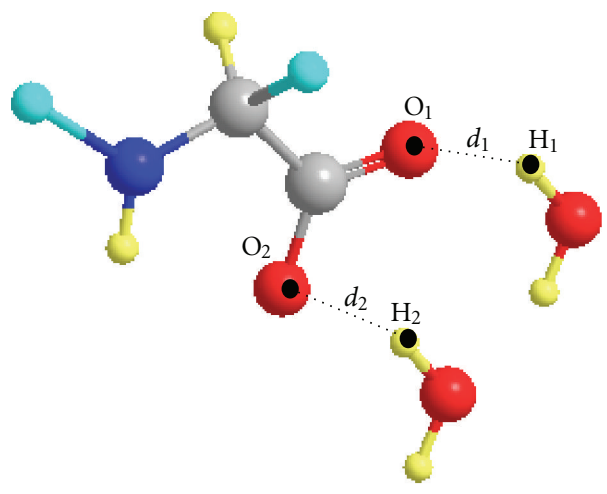

(a)

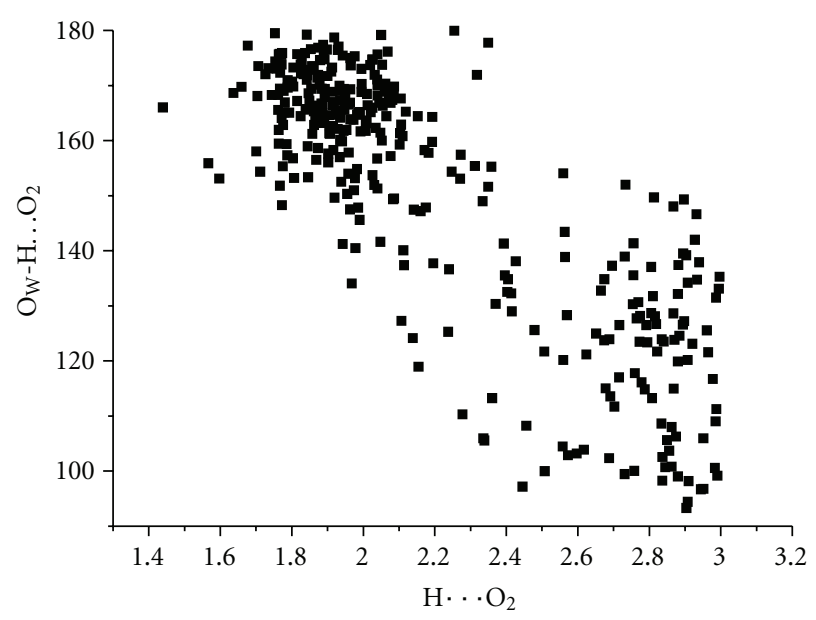

(b)

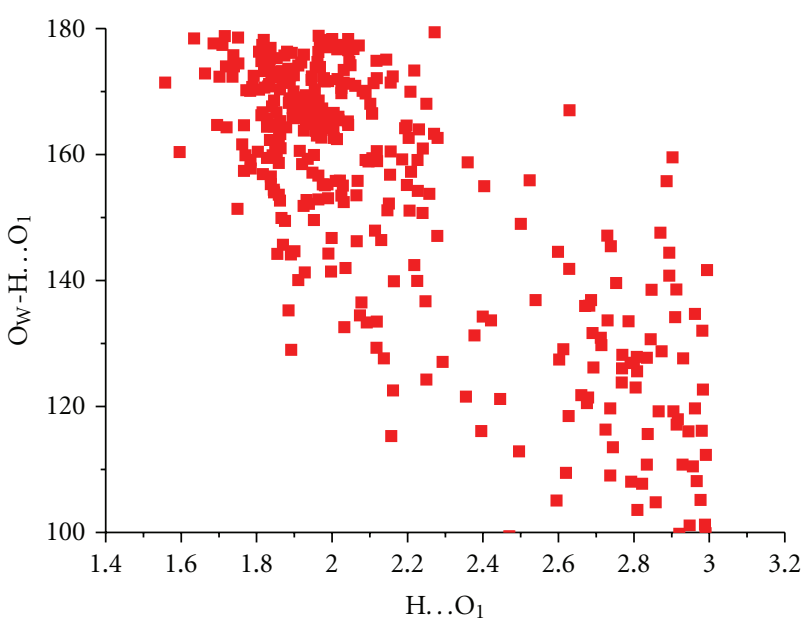

(c)

Figure 6: Cambridge Crystallographic Database (CSD) search query for the structural mode (a) C (gray), N (blue), any group (cyan), H (light-yellow), and $\mathrm{O}$ (red) of a bound water molecule to carboxylates. Correlations between $\mathrm{O}_{\mathrm{W}}-\mathrm{H} \cdots \mathrm{O}_{2}$ distances and $\mathrm{O}_{\mathrm{W}}-\mathrm{H} \cdot \cdots \mathrm{O}_{2}$ angles (b) and $\mathrm{O}_{\mathrm{W}}-\mathrm{H} \cdots \mathrm{O}_{1}$ distances and $\mathrm{O}_{\mathrm{W}}-\mathrm{H} \cdots \mathrm{O}_{1}$ angles (c).

formed [35], particular attention has been given to the hydrogen bond patterns in the vicinity of the carboxylate group that involves two simultaneous hydrogen acceptors. The concept of five- and six-membered conjugated rings, along with three-center (bifurcated) and 4-center (trifurcated) hydrogen bonds, has been acknowledged and accepted widely as an important factor in determining the structure and function of molecules ranging from inorganic to organic and biological molecules [1, 35-39]. Furthermore, Port and Pullman [40] studied theoretically the formate ion-water interaction as a prototype of the carboxylate group. Three energetically favourable hydration sites were obtained, two equivalent sites on the carboxylate oxygens at the exterior of the ion and one water bridging the two oxygen atoms.

The ConQuest 1.13 program was used for all the statistical analysis described in this paper. Specifically, the CSD version 5.32 (November 2010) for small molecules was searched, with the following general search flags: $R>0.5$, "3D coordinates", and "only organic".
In order to extract the number of entries present in the current database that form six-membered conjugated rings between the two oxygens of the $\alpha$-carboxylate and the carboxylic group with a molecule of water in the vicinity, the following geometric cut-offs were used: upper limits $d=3 \AA$ for $\left(\mathrm{O}_{\mathrm{w}}\right)-\mathrm{H} \cdots \mathrm{O}=\mathrm{C}$ and $\left(\mathrm{O}_{\mathrm{w}}\right)-\mathrm{H} \cdots{ }^{-} \mathrm{O}-\mathrm{C}$, and $d^{\prime}=3.5 \AA$ for $\mathrm{O}_{\mathrm{w}} \cdots \mathrm{O}=\mathrm{C}$ and $\mathrm{O}_{\mathrm{w}} \cdots{ }^{-} \mathrm{O}-\mathrm{C} .44$ hits were obtained for the carboxylate state (Figure 5), whereas only one was derived for the protonated form. Therefore, the number of structures of carboxylates is sufficient to give reasonable statistics. Figure 5 demonstrates that the oxygen of water, $\mathrm{O}_{\mathrm{w}}$, is reasonably close to the carboxylate oxygens and displays a significant preference for the $\mathrm{O}_{1}-\mathrm{C}-\mathrm{O}_{2}$ carboxylate plane.

There is a general correlation between hydrogen bond lengths and hydrogen bond angles (Figure 6) similar to that observed by Jeffrey and Maluszynska [41] in the case of water molecules in the hydrates of small biological molecules. Shortening of the $\mathrm{O}_{\mathrm{W}}-\mathrm{H} \cdots \mathrm{O}_{2}$ and $\mathrm{O}_{\mathrm{W}}-\mathrm{H} \cdot \cdots \mathrm{O}_{1}$ distances implies larger $\mathrm{O}_{\mathrm{W}}-\mathrm{H} \cdots \mathrm{O}_{1}$ and $\mathrm{O}_{\mathrm{W}}-\mathrm{H} \cdots \mathrm{O}_{2}$ angles. 


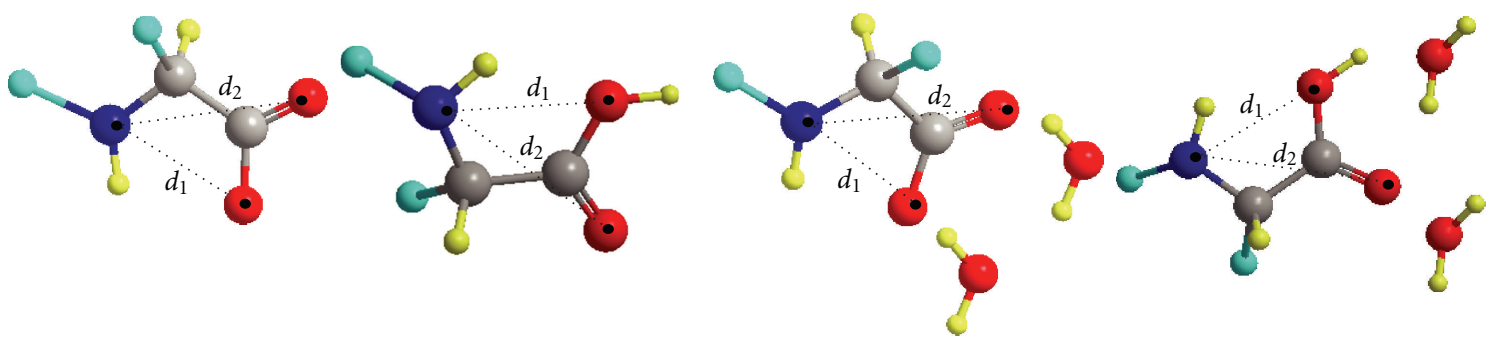

(a)

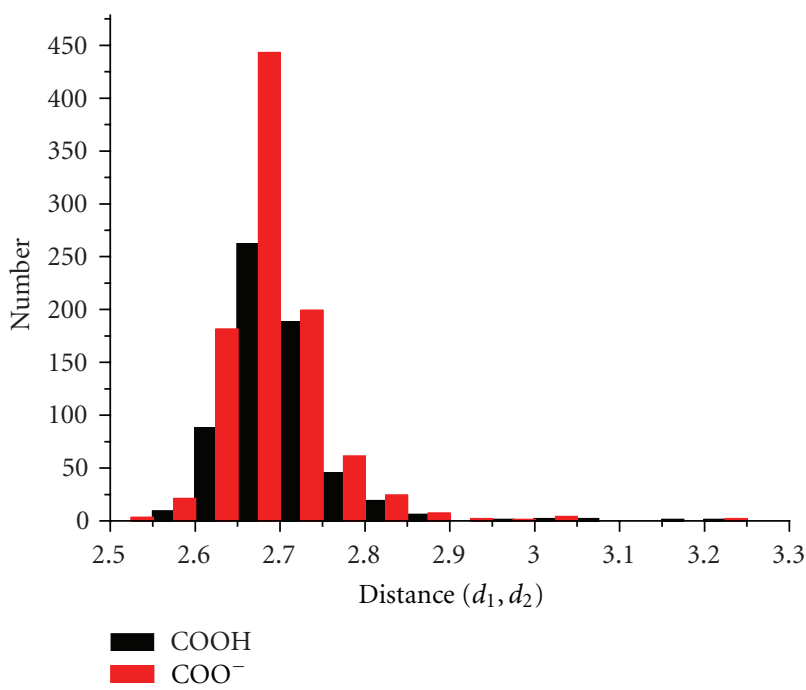

(b)

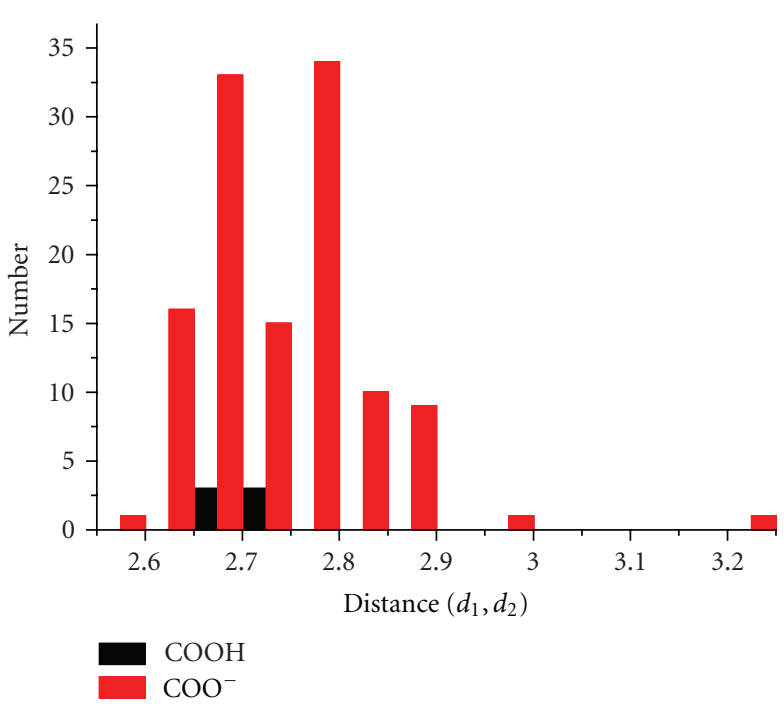

(c)

FIgure 7: (a) Cambridge Crystallographic Database (CSD) search queries for intramolecular hydrogen bond in the presence and in the absence of two water molecules bound to the carboxylate and carboxylic groups, respectively. C (gray), N (blue), any group (cyan), $\mathrm{H}$ (lightyellow), and $\mathrm{O}$ (red). (b) Plot of the number of structures versus the distances $d_{1}\left(\mathrm{~N} \cdots \mathrm{O}^{-}\right)$and $d_{2}(\mathrm{~N} \cdots \mathrm{O}=\mathrm{C})$ in the absence of a water molecule. (c) Plot of the number of structures versus the distances $d_{1}\left(\mathrm{~N} \cdots \mathrm{O}^{-}\right)$and $d_{2}(\mathrm{~N} \cdots \mathrm{O}=\mathrm{C})$ in the presence of two water molecules bound to the carboxylate and the carboxylic groups, respectively.

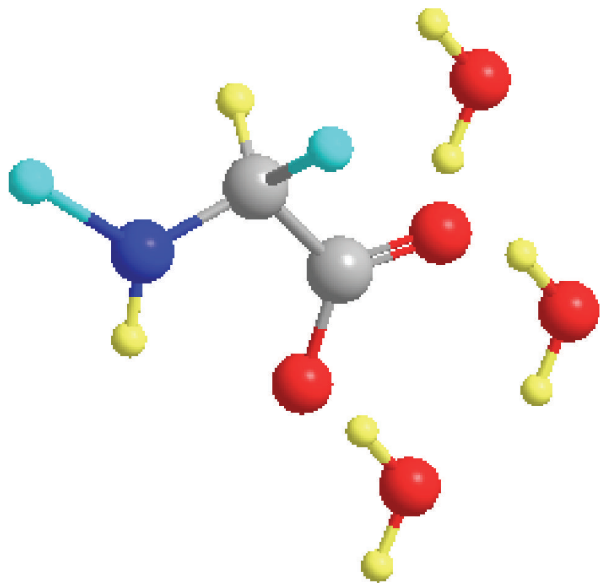

(a)

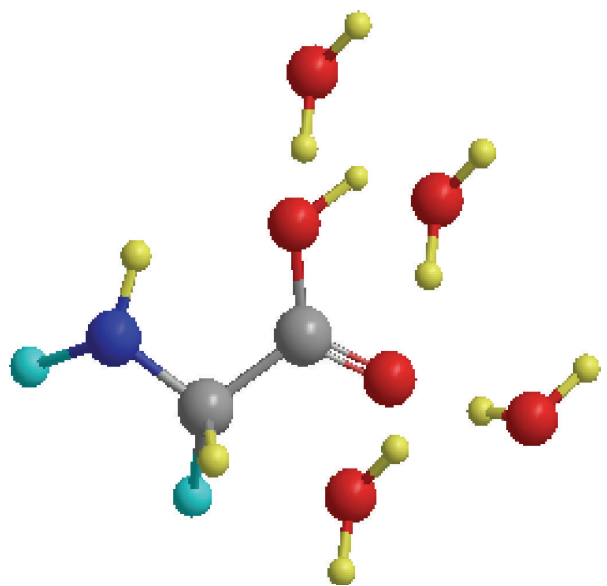

(b)

FIgURE 8: Tentative models for the hydration sites of the $\alpha$-carboxylic (a) and carboxylate (b) group of amino acids and their derivatives. C (gray), $\mathrm{N}$ (blue), any group (cyan), $\mathrm{H}$ (light-yellow), and $\mathrm{O}$ (red). 
Furthermore, crystallographic database searches were performed to identify the propensity for the formation of intramolecular hydrogen bond interaction in the carboxylate $\left(\mathrm{NH} \cdots \mathrm{O}^{-}\right)$and the carboxylic acid $(\mathrm{NH} \cdots \mathrm{O}=\mathrm{C})$ state. Interestingly, 946 and 118 hits were retrieved for the carboxylate and 621 and 6 hits for the carboxylic form in the absence and presence of two molecules of water, respectively. It is evident from Figure 7 that in the presence of two bound water molecules there is a significant reduction in the number of structures with intramolecular hydrogen bond interaction for the carboxylate group and, concurrently, a significant increase in the distance $\left(\mathrm{NH} \cdots \mathrm{O}^{-}\right)$. It is important to note that no intramolecular ${ }^{+} \mathrm{NH}_{3} \ldots{ }^{-} \mathrm{OOC}$ hydrogen bonds were observed for 82 amino acid carboxylates with $\mathrm{sp}^{3}$-hybridized $C^{\beta}$-atoms [42] in agreement with an early survey of amino acid structures determined by neutron diffraction [43].

\section{Conclusions}

${ }^{17} \mathrm{O}$ shielding changes of amino acids as a function of molar fraction of $\mathrm{DMSO} / \mathrm{H}_{2} \mathrm{O}$, the decrease in the longitudinal relaxation times $\left(T_{1}\right)$ of $\mathrm{C}_{\alpha} \mathrm{D}$ and ${ }^{13} \mathrm{C}_{\alpha}$, and the increase in line widths of ${ }^{14} \mathrm{~N}$ and ${ }^{17} \mathrm{O}$ at acidic $\mathrm{pH}$ relative to those at neutral $\mathrm{pH}$ may be interpreted with the hypothesis that the cationic form of amino acids is more hydrated by 1 to 3 molecules of water than the zwitterionic form. Similar behaviour was also observed for acetylated derivatives of amino acids, but not for betaines, between the protonated and deprotonated carboxyl group. Although the precise hydration differences observed for various nuclei deviate somehow, it may be concluded that these hydrated complexes have lifetimes that are shorter than the NMR chemical shift time scale, but presumably longer than the overall molecular rotational correlation time of 2-10 ps. An exhaustive search in the Cambridge Crystallographic Database (CSD) demonstrates a strong tendency of the two oxygens of the deprotonated carboxylate group to form hydrogen bonds with a single molecule of water. Even though statistical analysis of structural parameters in crystals cannot be used in a straightforward way to derive quantitative structural models in solution, it is of interest to note that this mode of six-membered conjugated ring, which is absent in the case of the carboxylic group, might result in a more compact and, thus, less hydrated structure in aqueous solution, in accordance with the NMR data (Figure 8).

Furthermore, it may be concluded that the bound molecules of water alleviate the $\mathrm{NH} \cdots \mathrm{O}^{-}$interaction and very probably this effect is even more pronounced in aqueous solution. From the above, it is evident that the reduced hydration of the carboxylate group, relative to the carboxylic group, should be attributed mainly to the strong tendency of the carboxylate group to form a six-membered conjugated ring with a single molecule of water. The $\mathrm{NH} \cdots \mathrm{O}^{-}$intramolecular hydrogen bond very probably plays an insignificant role. Constructively, the tentative models illustrated in Figure 8 should be further validated by in silico and experimental approaches. Computational methods complement the experimental results by providing information on the microscope and physicochemical details on the interplay between water and the biomolecule of interest [44-47]. For example, introduction of solvent effects into molecular dynamics can provide an atomic description of the folding and unfolding of a protein [47]. Furthermore, there is an array of theoretical approaches that have been utilized for treating NMR shieldings in solution [48], that can be classified as continuum models $[49,50]$ and molecular dynamics simulations [51]. Experimental approaches could involve ${ }^{17} \mathrm{O}$ NMR both in powders and in the crystal state [52] with varying degrees of hydration.

\section{Acknowledgments}

The authors are deeply indebted to Assistant Professor A. N. Troganis and Dr. P. G. Takis (Department of Biological Applications and Technologies, University of Ioannina, Greece) and Assistant Professor V. S. Melissas (Department of Chemistry, University of Ioannina, Greece) for communicating to them research results prior to publication [32].

\section{References}

[1] G. A. Jeffrey and W. Saenger, Hydrogen Bonding in Biological Structures, Springer, New York, NY, USA, 1991.

[2] I. P. Gerothanassis, "Multinuclear and multidimensional NMR methodology for studying individual water molecules bound to peptides and proteins in solution: principles and applications," Progress in Nuclear Magnetic Resonance Spectroscopy, vol. 26, no. 3, pp. 171-237, 1994.

[3] G. D. Rose and R. Wolfenden, "Hydrogen bonding, hydrophobicity, packing, and protein folding," Annual Review of Biophysics and Biomolecular Structure, vol. 22, pp. 381-415, 1993.

[4] Y. Levy and J. N. Onuchic, "Water mediation in protein folding and molecular recognition," Annual Review of Biophysics and Biomolecular Structure, vol. 35, pp. 389-415, 2006.

[5] Y. Levy, J. Jortner, and O. M. Becker, "Solvent effects on the energy landscapes and folding kinetics of polyalanine," Proceedings of the National Academy of Sciences of the United States of America, vol. 98, no. 5, pp. 2188-2193, 2001.

[6] J. C. Covalt, M. Roy, and P. A. Jennings, "Core and surface mutations affect folding kinetics, stability and cooperativity in IL-1 $\beta$ : does alteration in buried water play a role?" Journal of Molecular Biology, vol. 307, no. 2, pp. 657-669, 2001.

[7] M. S. Cheung, A. E. García, and J. N. Onuchic, "Protein folding mediated by solvation: water expulsion and formation of the hydrophobic core occur after the structural collapse," Proceedings of the National Academy of Sciences of the United States of America, vol. 99, no. 2, pp. 685-690, 2002.

[8] Y. Van Haverbeke, R. N. Muller, and L. Vander Elst, "pH-induced motional and conformational changes of amino acids. A reexamination by deuterium longitudinal nuclear relaxation," Journal of Physical Chemistry, vol. 88, no. 21, pp. 49784980, 1984.

[9] A. Spisni, E. D. Gotsis, and D. Fiat, " ${ }^{17} \mathrm{O}$ NMR investigation of the hydration of L-Alanine and L-Proline in water/Me $\mathrm{M}_{2} \mathrm{SO}$ mixtures," Biochemical and Biophysical Research Communications, vol. 135, no. 2, pp. 363-366, 1986.

[10] J. Lauterwein, I. P. Gerothanassis, R. N. Hunston, and M. Schumacher, "17 O NMR relaxation times of the protein amino 
acids in aqueous solution. Estimation of the relative hydration numbers in the cationic, anionic, and zwitterionic forms," Journal of Physical Chemistry, vol. 95, no. 9, pp. 3804-3811, 1991.

[11] A. N. Troganis, C. Tsanaktsidis, and I. P. Gerothanassis, " ${ }^{14} \mathrm{~N}$ NMR relaxation times of several protein amino acids in aqueous solution-comparison with ${ }^{17} \mathrm{O}$ NMR data and estimation of the relative hydration numbers in the cationic and zwitterionic forms," Journal of Magnetic Resonance, vol. 164, no. 2, pp. 294-303, 2003.

[12] I. P. Gerothanassis, "Oxygen-17 NMR spectroscopy: basic principles and applications (part II)," Progress in Nuclear Magnetic Resonance Spectroscopy, vol. 57, no. 1, pp. 1-110, 2010.

[13] I. P. Gerothanassis, "Oxygen-17 NMR spectroscopy: basic principles and applications (Part I)," Progress in Nuclear Magnetic Resonance Spectroscopy, vol. 56, no. 2, pp. 95-197, 2010.

[14] J. L. Hollenberg and J. B. Ifft, "Hydration numbers by nearinfrared spectrophotometry. 1. Amino acids," Journal of Physical Chemistry, vol. 86, no. 11, pp. 1938-1941, 1982.

[15] B. Hernández, F. Pflüger, M. Nsangou, and M. Ghomi, "Vibrational analysis of amino acids and short peptides in hydrated media. IV. amino acids with hydrophobic side chains: $L^{-}$ Alanine, ${ }_{L}$-Valine, and ${ }_{L}$-Isoleucine," Journal of Physical Chemistry B, vol. 113, no. 10, pp. 3169-3178, 2009.

[16] R. M. Balabin, "The first step in glycine solvation: the glycinewater complex," Journal of Physical Chemistry B, vol. 114, no. 46, pp. 15075-15078, 2010.

[17] M. J. Locke and R. T. McIver, "Effect of solvation on the acid/ base properties of glycine," Journal of the American Chemical Society, vol. 105, no. 13, pp. 4226-4232, 1983.

[18] J. L. Alonso, E. J. Cocinero, A. Lesarri, M. E. Sanz, and J. C. López, "The glycine-water complex," Angewandte ChemieInternational Edition, vol. 45, no. 21, pp. 3471-3474, 2006.

[19] D. Fiat, T. E. St Amour, M. I. Burgar, A. Steinschneider, B. Valentine, and D. Dhawan, " ${ }^{17} \mathrm{O}$ nuclear magnetic resonance and its biological applications," The Bulletin of Magnetic Resonance, vol. 1, p. 18, 1980.

[20] J. G. Pearson and E. Oldfield, " 17 O NMR: applications in biochemistr," in Encyclopedia of Nuclear Magnetic Resonance, D. M. Grant and R. K. Harris, Eds., pp. 3440-3443, John Wiley \& Sons, 1995.

[21] D. W. Boykin, ${ }^{17}$ O NMR Spectroscopy in Organic Chemistry, CRC Press, Boston, Mass, USA, 1991.

[22] S. Berger, S. Braun, and H. O. Kalinowski, NMR Spectroscopy of Non-Metallic Elements, John Wiley \& Sons, Chichester, UK, 1997.

[23] J. Lauterwein, I. P. Gerothanassis, and R. N. Hunston, " ${ }^{17} \mathrm{O}$ NMR of enriched acetic-acid, glycine, glutamic-acid and aspartic-acid in aqueous-solution.1. Chemical-shift studies," Helvetica Chimica Acta, vol. 65, no. 6, pp. 1764-1773, 1982.

[24] J. Lauterwein, I. P. Gerothanassis, and R. N. Hunston, " ${ }^{17} \mathrm{O}$ NMR of enriched acetic-acid, glycine, glutamic-acid and aspartic-acid in aqueous-solution.2. Relaxation studies," Helvetica Chimica Acta, vol. 65, no. 6, pp. 1774-1784, 1982.

[25] A. Steinschneider, M. I. Burgar, A. Buku, and D. Fiat, "Labeling of amino acids and peptides with isotopic oxygen as followed by ${ }^{17} \mathrm{O}$ NMR," International Journal of Peptide and Protein Research, vol. 18, no. 3, pp. 324-333, 1981.

[26] B. Valentine, T. S. Amour, R. Walter, and D. Fiat, "pH dependence of oxygen-17 chemical shifts and linewidths of l-alanine and glycine," Journal of Magnetic Resonance, vol. 38, no. 3, pp. 413-418, 1980.

[27] G. W. Kabalka and N. M. Goudgaon, " ${ }^{17} \mathrm{O}$ enrichment methods," in ${ }^{17}$ O NMR Spectroscopy in Organic Chemistry, D. W.
Boykin, Ed., chapter 2, pp. 21-37, CRC Press, Boston, Mass, USA, 1991.

[28] T. Karayannis, I. P. Gerothanassis, M. Sakarellos-Daitsiotis, C. Sakarellos, and M. Marraud, " ${ }^{17} \mathrm{O}-$ and ${ }^{14} \mathrm{~N}-\mathrm{nmr}$ studies of leu-enkephalin and enkephalin-related fragments in aqueous solution," Biopolymers, vol. 29, no. 2, pp. 423-439, 1990.

[29] J. Reuben, "Hydrogen-bonding effects on oxygen-17 chemical shifts," Journal of the American Chemical Society, vol. 91, no. 21, pp. 5725-5729, 1969.

[30] J. Tritt Goc and D. Fiat, "Determination of dynamic parameters in amino-acids from ${ }^{17} \mathrm{O}$ NMR line-width measurements," Magnetic Resonance in Chemistry, vol. 29, no. 2, pp. 156-163, 1991.

[31] D. E. Woessner, "Nuclear magnetic dipole-dipole relaxation in molecules with internal motion," The Journal of Chemical Physics, vol. 42, no. 6, pp. 1855-1859, 1965.

[32] P. G. Takis, V. S. Melissas, and A. N. Troganis, private communication, 2011.

[33] C. H. Gorbitz, "Hydrogen-bond distances and angles in the structures of amino-acids and peptides," Acta Crystallogrica B, vol. 45, pp. 390-395, 1989.

[34] E. Arunan, G. R. Desiraju, R. A. Klein et al., "Defining the hydrogen bond: an account (IUPAC Technical Report)," Pure and Applied Chemistry, vol. 83, no. 8, pp. 1619-1636, 2011.

[35] C. B. Aakeröy and K. R. Seddon, "The hydrogen bond and crystal engineering," Chemical Society Reviews, vol. 22, no. 6, pp. 397-407, 1993.

[36] T. Steiner, "The hydrogen bond in the solid state," Angewandte Chemie-International Edition, vol. 41, no. 1, pp. 49-76, 2002.

[37] R. Taylor, O. Kennard, and W. Versichel, "Geometry of the $\mathrm{NH} \cdots \mathrm{O}=\mathrm{C}$ hydrogen bond. 2. Three-center ("bifurcated") and four-center (("trifurcated") bonds," Journal of the American Chemical Society, vol. 106, no. 1, pp. 244-248, 1984.

[38] L. Infantes and W. D. S. Motherwell, "Hydrogen bond competition between chemical groups: new methodology and the Cambridge Structural Database," Zeitschrift fur Kristallographie, vol. 220, no. 4, pp. 333-339, 2005.

[39] R. Taylor, O. Kennard, and W. Versichel, "The geometry of the $\mathrm{NH} \cdots \mathrm{O}=\mathrm{C}$ hydrogen-bond .3. Hydrogen-bond distances and angles," Acta Crystallographica B, vol. 40, pp. 280-288, 1984.

[40] G. N. J. Port and A. Pullman, "Quantum-mechanical studies of environmental effects on biomolecules. III. Ab-initio model studies of hydration of peptides and proteins," International Journal of Quantum Chemistry, vol. 8, supplement 1, pp. 2132, 1974.

[41] G. A. Jeffrey and H. Maluszynska, "The stereochemistry of the water molecules in the hydrates of small biological molecules," Acta Crystallographica. Section B, vol. 46, part 4, pp. 546-549, 1990.

[42] C. H. Görbitz and M. C. Etter, "Hydrogen bonds to carboxylate groups. Syn/anti distributions and steric effects," Journal of the American Chemical Society, vol. 114, no. 2, pp. 627-631, 1992.

[43] T. F. Koetzle and M. S. Lehmann, "The hydrogen bondrecent developments," in Theory and Experiments, P. Schuster, G. Zundel, and C. Sandorfy, Eds., chapter 2, pp. 457-469, North Holland, Amsterdam, The Netherlands, 1976.

[44] S. Xu, J. M. Nilles, and K. H. Bowen, "Zwitterion formation in hydrated amino acid, dipole bound anions: how many water molecules are required?" The Journal of Chemical Physics, vol. 119, no. 20, pp. 10696-10701, 2003.

[45] S. Tiwari, P. C. Mishra, and S. Suhai, "Solvent effect of aqueous media on properties of glycine: significance of specific and 
bulk solvent effects, and geometry optimization in aqueous media," International Journal of Quantum Chemistry, vol. 108, no. 5, pp. 1004-1016, 2008.

[46] S. M. Bachrach, "Microsolvation of glycine: a DFT study," Journal of Physical Chemistry A, vol. 112, no. 16, pp. 37223730, 2008.

[47] A. E. García and J. N. Onuchic, "Folding a protein in a computer: an atomic description of the folding/unfolding of protein A," Proceedings of the National Academy of Sciences of the United States of America, vol. 100, no. 2, pp. 13898-13903, 2003.

[48] A. C. De Dios, "Ab initio calculations of the NMR chemical shift," Progress in Nuclear Magnetic Resonance Spectroscopy, vol. 29, no. 3-4, pp. 229-278, 1996.

[49] R. A. Klein, B. Mennucci, and J. Tomasi, "Ab initio calculations of ${ }^{17} \mathrm{O}$ NMR-chemical shifts for water. The limits of PCM theory and the role of hydrogen-bond geometry and cooperativity," Journal of Physical Chemistry A, vol. 108, no. 27, pp. 5851-5863, 2004.

[50] A. Klamt, B. Mennucci, J. Tomasi et al., "On the performance of continuum solvation methods. A comment on "Universal Approaches to Solvation Modeling"', Accounts of Chemical Research, vol. 42, no. 4, pp. 489-492, 2009.

[51] V. G. Malkin, O. L. Malkina, G. Steinebrunner, and H. Huber, "Solvent effect on the NMR chemical shieldings in water calculated by a combination of molecular dynamics and density functional theory," Chemistry, vol. 2, pp. 452-457, 1996.

[52] G. Wu, "Solid-state ${ }^{17} \mathrm{O}$ NMR studies of organic and biological molecules," Progress in Nuclear Magnetic Resonance Spectroscopy, vol. 52, no. 2-3, pp. 118-169, 2008. 

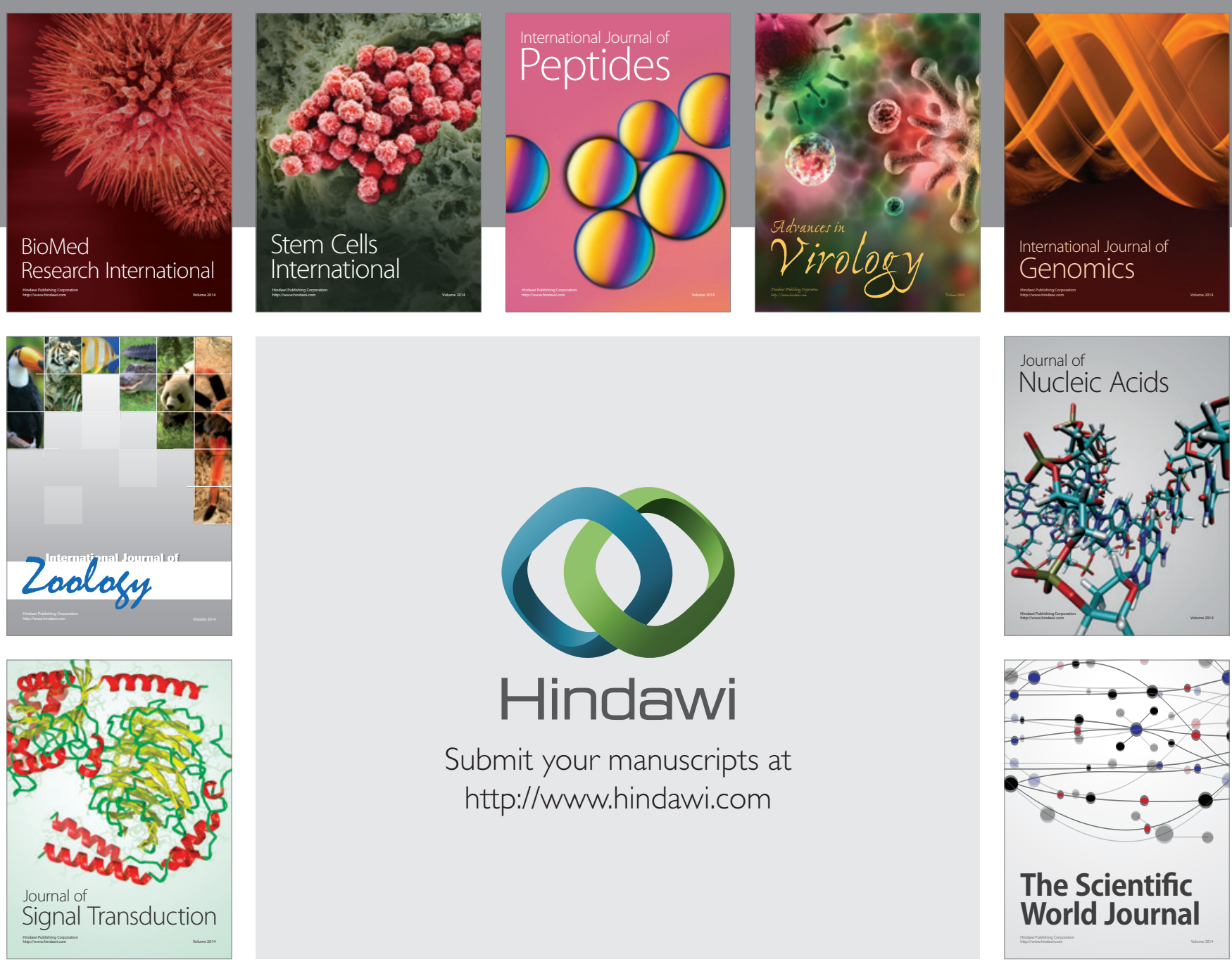

Submit your manuscripts at

http://www.hindawi.com
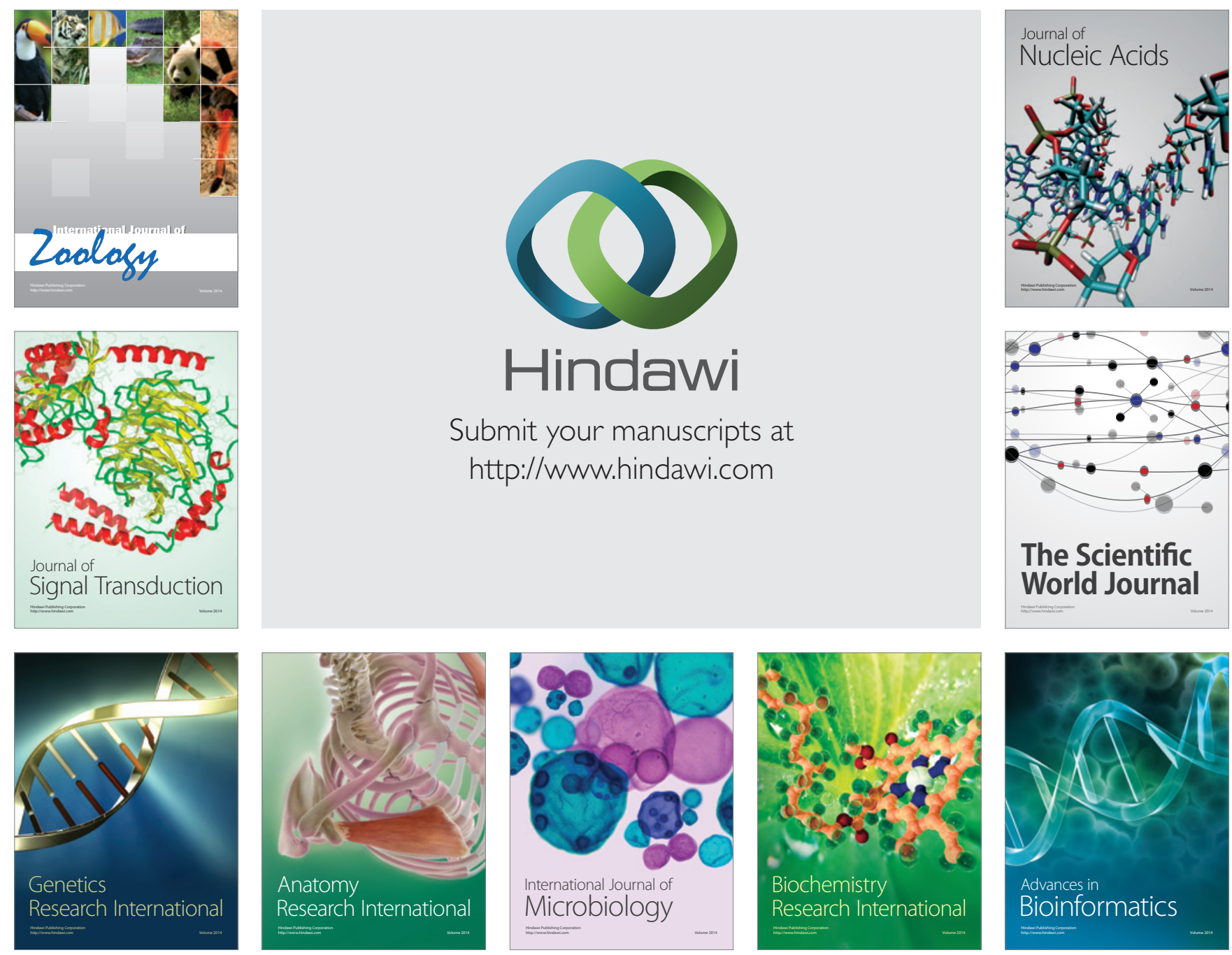

The Scientific World Journal
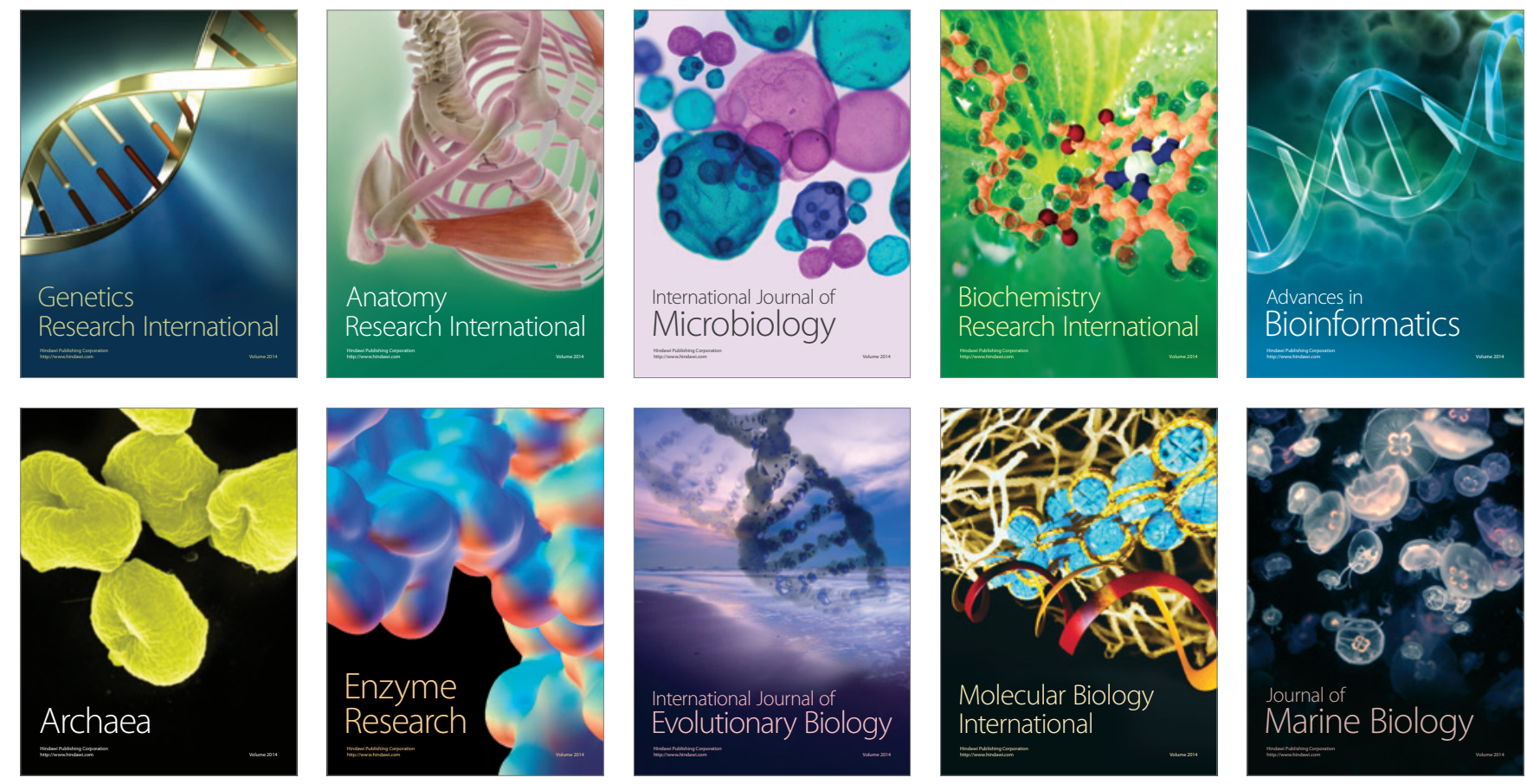